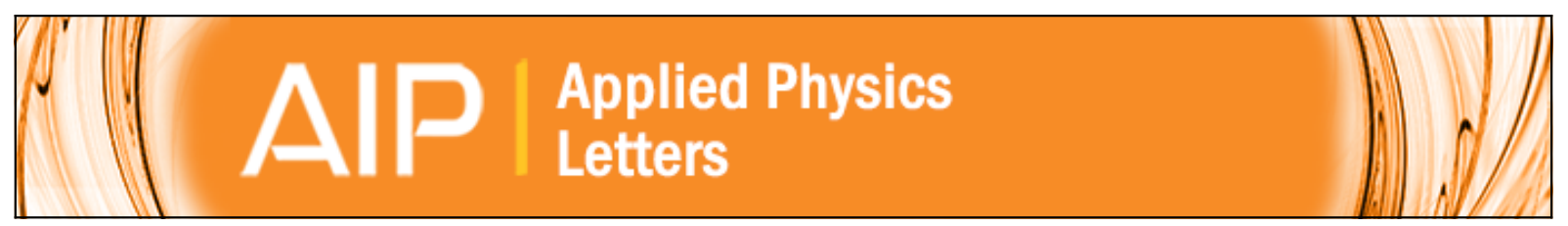

\title{
Relationship between martensitic plate size and austenitic grain size in martensitic transformations
}

P. La Roca, L. Isola, Ph. Vermaut, and J. Malarría

Citation: Applied Physics Letters 106, 221903 (2015); doi: 10.1063/1.4922195

View online: http://dx.doi.org/10.1063/1.4922195

View Table of Contents: http://scitation.aip.org/content/aip/journal/apl/106/22?ver=pdfcov

Published by the AIP Publishing

\section{Articles you may be interested in}

Grain boundary and triple junction constraints during martensitic transformation in shape memory alloys

J. Appl. Phys. 114, 053503 (2013); 10.1063/1.4817170

Actuation micro-design based on martensitic phase transformations in shape memory alloys

AIP Conf. Proc. 1472, 135 (2012); 10.1063/1.4748080

Entropy change linked to the magnetic field induced martensitic transformation in a Ni-Mn-In-Co shape memory alloy

J. Appl. Phys. 107, 053501 (2010); 10.1063/1.3318491

Internal friction peak associated with the interface motion in the martensitic transformation of CuAINiMnTi shape memory alloy

J. Appl. Phys. 102, 023521 (2007); 10.1063/1.2757203

In situ photoelectron emission microscopy of a thermally induced martensitic transformation in a CuZnAl shape memory alloy

Appl. Phys. Lett. 88, 091910 (2006); 10.1063/1.2177450

Frustrated by

old technology?

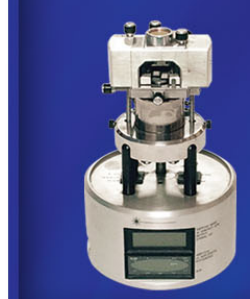

Is your AFM dead

and can't be repaired?

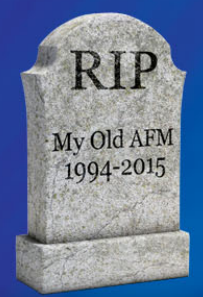

Sick of bad customer support?

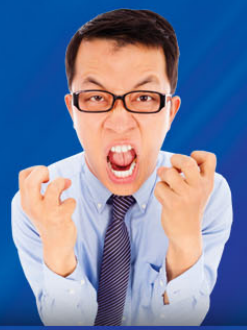

It is time to upgrade your AFM

Minimum $\$ 20,000$ trade-in discount for purchases before August 31st

Asylum Research is today's technology leader in AFM 


\title{
Relationship between martensitic plate size and austenitic grain size in martensitic transformations
}

\author{
P. La Roca, ${ }^{1}$ L. Isola, ${ }^{1}$ Ph. Vermaut, ${ }^{2}$ and J. Malarría ${ }^{1, a)}$ \\ ${ }^{1}$ Instituto de Física Rosario (CONICET-Universidad Nacional de Rosario), Bvrd. 27 de Febrero 210 Bis, \\ S2000EZP Rosario, Argentina \\ ${ }^{2}$ Institut de Recherche de Chimie Paris, CNRS - Chimie ParisTech, 11 rue Pierre et Marie Curie, 75005 Paris, \\ France and Université Pierre et Marie Curie, 4 Place Jussieu, 75231 Paris, France
}

(Received 30 March 2015; accepted 25 May 2015; published online 3 June 2015)

\begin{abstract}
A systematic experimental analysis based on an assessment of the mean martensite plate size $\left(h_{\text {plate }}\right)$ in sub-grain domains was implemented to characterize the martensite morphology in polycrystalline $\mathrm{Cu}$-based shape memory alloys. In the grain size range below $100 \mu \mathrm{m}$, a linear relationship between the average width of the martensite plates and the mean grain size was obtained for a thermalinduced martensitic transformation. This evaluation allows us to perform an analysis of how microstructural length scales affect the martensitic transformation. (C) 2015 AIP Publishing LLC.

[http://dx.doi.org/10.1063/1.4922195]
\end{abstract}

In shape memory alloys (SMA), the grain size $(d)$ can be reduced in order to improve the mechanical properties. ${ }^{1}$ This is effective, for instance, in enhancing fracture toughness in Cu-based SMA, although the grain size reduction yields a change in the transformation temperatures. This effect has been noted by a large number of authors. It has been shown that for $d$ greater than $100 \mu \mathrm{m}$, the start temperature of the martensitic transformation $\left(M_{s}\right)$ is generally independent of $d$. However, the $M_{s}$ decreases when $d$ is reduced below $100 \mu \mathrm{m}$. This behavior was observed for different shape memory polycrystalline alloys: $\mathrm{Fe}-\mathrm{Pd}{ }^{2} \mathrm{Cu}-\mathrm{Zn}-\mathrm{Al} \mathrm{l}^{3}$ and $\mathrm{Cu}-\mathrm{Al}-\mathrm{Ni}{ }^{4}$

There are other phenomena related to grain size, which can affect the transformation and material properties. When a phase transformation occurs, the austenite grain-size reduction yields a smaller martensite plate size. ${ }^{5}$ In the seventies, this phenomenon had some impact in the scientific community because a Hall-Petch relation between the yield stress and the martensitic plate width was discovered. ${ }^{6}$ Therefore, the material yield stress is increased through the decrease of the martensitic plate size, and the relation $h_{\text {plate }} \propto d^{1 / 3}$ between plate and grain size was determined by fitting experimental data over a limited range of the grain size. ${ }^{7}$

Also, in the last ten years, the community has concentrated its efforts in the study of "size effects." " consequence of a reduction in the different macro or microstructure characteristic parameters of the material, like grain size, micro-wire diameter, thin film thickness, or particle size. The implications that these effects have on the superelasticity and shape memory behavior has gained importance due to the potential use of these materials in small scale devices. ${ }^{9,12,13}$

Size effects on characteristic features of the martensitic transformation, such as $M_{s}$, hysteresis, or the critical transformation stress, are related to energy barriers that obstruct or delay the progress of the martensitic transformation. Various size related contributions have been considered to

a)malarria@ifir-conicet.gov.ar explain variations in $M_{s}$, hysteresis, or transformation/ reverse transformation stresses. Such size related contributions include sample geometry, grain size, and whether the transformation takes place in constrained structures (as nanocrystalline materials) or unconstrained ones (as nano pillars with free surfaces). ${ }^{10}$ For example, in nanopillars, size effects appear to be mainly related to the relief of elastic transformation stresses at free surfaces, a nearly instantaneous dissipation of the heat generated in the transformation, and frictional work spent in overcoming resistance to interface motion dominated by pinning defects at the pillar surface. ${ }^{9,11}$ In polycrystals with small grains, where the martensitic transformation can be constrained by the grain boundaries, the interphase energy between martensite and austenite and the interfacial energy between martensite variants become important. In non-thermoelastic transformations, the surface energy related to the austenite-martensite habit planes plays a substantial role in the suppression of transformation at smaller grain sizes. ${ }^{14}$ In thermoelastic martensitic transformations, the number of phase boundaries is reduced to zero after a full transformation, while the density of martensite-martensite boundaries increases. If this later phenomenon were dominant it would suppress the martensitic transformation. For instance, in nanostructured $\mathrm{Ni}-\mathrm{Ti}$, the grain size effect on the thermal-induced martensitic transformation has been investigated..$^{15}$ It was found that the martensitic transformation is completely suppressed when the grain size is less than $50 \mathrm{~nm}$. This effect was attributed mainly to the presence of an energy barrier related to the martensite-martensite $(\mathrm{m}-\mathrm{m})$ interface energy and the authors used a relation $h_{\text {plate }} \propto d^{1 / 2}$ to assess the m-m interface energy change with decreasing values of $d$.

On the other hand, the martensitic plate size and the m$m$ interface energy are very important parameters for theoretical models, which describe the SMA behavior in the presence of size effects. ${ }^{15-17}$ The analysis of this particular point constitutes the scope of the present work, where a systematic experimental study of the relation between $d$ and $h_{\text {plate }}$ is presented for values of $d$ ranging from $500 \mathrm{~nm}$ to $6 \mathrm{~mm}$. This 
TABLE I. List of samples produced by rapid solidification techniques with their casting parameters and mean grain size in as cast state.

\begin{tabular}{lcccc}
\hline \hline Sample & Alloys (at. \%) & Tech. & Speed $(\mathrm{m} / \mathrm{s})$ & $d(\mu \mathrm{m})$ \\
\hline MS1 & $C u-13 \mathrm{Al}-5 \mathrm{Ni}$ & MS & 19 & 3 \\
MS2 & $C u-13 \mathrm{Al}-5.5 \mathrm{Ni}-1 \mathrm{Ti}$ & MS & 19 & $1-2$ \\
TR1 & $\mathrm{Cu}-13 \mathrm{Al}-5 \mathrm{Ni}$ & TRC & 0.6 & 24 \\
TR2 & $\mathrm{Cu}-13 \mathrm{Al}-5.5 \mathrm{Ni}-1 \mathrm{Ti}$ & TRC & 0.84 & 5 \\
\hline \hline
\end{tabular}

relation allows us to evaluate the change of martensitic interface energy per unit volume as $d$ is reduced and to analyze how $d$ influences the martensitic transformations.

In order to perform a study over a wide range of grain sizes, different production techniques and thermal treatments were used. Rapid solidification techniques allow us to obtain polycrystalline materials with a grain size less than that produced by conventional techniques. For example, Melt Spinning (MS) and Twin Roll Casting (TRC) were successfully applied to $\mathrm{Cu}$-based SMA to develop samples with grain size less than $500 \mathrm{~nm} .{ }^{18-20}$ Then, ribbons $(50 \mu \mathrm{m}$ in thickness) and strips (300 $\mu \mathrm{m}$ in thickness) were produced by MS and TRC, respectively. Processing parameters, alloy chemical composition, and sample mean grain size are presented in Table I. In order to modify the as-cast grain size, different samples were annealed at $700^{\circ} \mathrm{C}, 800^{\circ} \mathrm{C}$, and $900^{\circ} \mathrm{C}$ for $30 \mathrm{~min}$, and then water quenched. A second thermal treatment was performed at $200^{\circ} \mathrm{C}$ for $15 \mathrm{~min}$ followed by air cooling, to release stress, promote order, and remove excess vacancies. In this manner, samples with a wide range of $d$, between $1 \mu \mathrm{m}$ and $100 \mu \mathrm{m}$, were obtained.

In addition to these rapid solidification samples, different pieces of a $\mathrm{Cu}-13 \mathrm{Al}-5 \mathrm{Ni}-(0.5 \mathrm{Ti}-0.1 \mathrm{Cr})$ at.\% wire were remelted and solidified at various cooling rates to produce a microstructure with grain sizes between $100 \mu \mathrm{m}$ and $1 \mathrm{~mm}$ (samples called T11). In order to extend our study to grain sizes grater than $1 \mathrm{~mm}$, single-crystals of $\mathrm{Cu}-13 \mathrm{Al}-5 \mathrm{Ni}$ produced by the Bridgman method were machined into cylinders of 2,4 , and $6 \mathrm{~mm}$ in diameter (see Table II).

Due to alloy compositions, all samples have transformation temperatures above room temperature. Thus, all of them are in the $18 \mathrm{R}$ martensitic phase at this temperature.

The microstructures of the samples with $d>10 \mu \mathrm{m}$ were studied with an Olympus PM3 optical microscope using

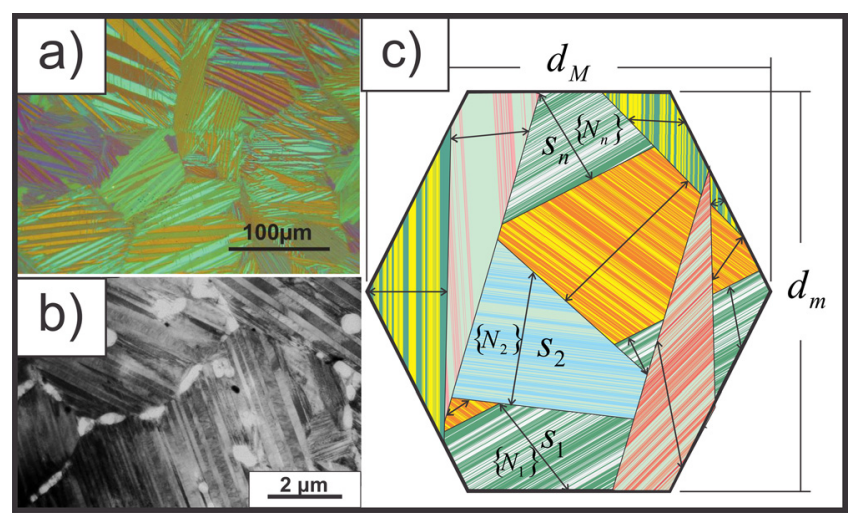

FIG. 1. Optical micrography of a large grain diameter microstructure (a), TEM bright field image of a small grain diameter microstructure (b) and the measurement method of $h_{\text {plate }}$ (c).
TABLE II. Coarse grain samples and single crystals.

\begin{tabular}{lccc}
\hline \hline Sample & Alloys (at. \%) & Tech. & Crystal size- $d(\mu \mathrm{m})$ \\
\hline$T 11$ & $\mathrm{Cu}-13 \mathrm{Al}-5 \mathrm{Ni}-(0.5 \mathrm{Ti}-0.1 \mathrm{Cr})$ & SDCS & $100-1000$ \\
$\mathrm{C} 2$ & $\mathrm{Cu}-\mathrm{Al}-\mathrm{Ni}$ & $\mathrm{BM}$ & 2000 \\
$\mathrm{C} 4$ & $\mathrm{Cu}-\mathrm{Al}-\mathrm{Ni}$ & $\mathrm{BM}$ & 4000 \\
$\mathrm{C6}$ & $\mathrm{Cu}-\mathrm{Al}-\mathrm{Ni}$ & $\mathrm{BM}$ & 6000 \\
\hline \hline
\end{tabular}

Nomarski interference contrast. These samples were electropolished with $20 \% \mathrm{H}_{2} \mathrm{SO}_{4}-47 \% \mathrm{H}_{3} \mathrm{PO}_{4}-\mathrm{H}_{2} \mathrm{O}$ for $30 \mathrm{~s}$ at $8 \mathrm{~V}$ and $5{ }^{\circ} \mathrm{C}$. The samples with smaller grain sizes were analyzed with a Philips EM300 transmission electron microscope (TEM). In this case, the thin foils were prepared with a twin-jet electropolisher using a $30 \% \mathrm{HNO}_{3}$-methanol solution at $-10{ }^{\circ} \mathrm{C}$.

To perform proper measurements of $h_{\text {plate }}$ and $d$ (reliable statistical results), it was necessary to take a large number of sample images in different grains using TEM and optical techniques. In particular, the $d$ value was calculated averaging the maximum $\left(d_{M}\right)$ and the minimum diameters $\left(d_{m}\right)$, that is, $d=\left(d_{M}+d_{m}\right) / 2$. In most of the grains, multiple parallel plate domains were observed in the martensitic structure and even in the self-accommodation structure (see Figure 1(a)). It is interesting to note that in most of the grains smaller than $10 \mu \mathrm{m}$ there was only one domain of parallel plates (see Figure 1(b)). This is similar to what was found in NiTi nano-grains, where the "herringbone" type of martensitic morphologies was observed. ${ }^{8}$ Thus, it was necessary to develop a measurement method to determine $h_{\text {plate }}$.

This method consists in drawing a line normal to the parallel plates in each domain (see Figure 1(c)). The line length $\left(S_{i}\right)$ was taken as the characteristic dimension of the martensitic domain and the number of intersections $\left(N_{i}\right)$ was determined. Then, the $h_{\text {plate }}$ of a given grain was calculated averaging the mean values of the martensitic plate size of each domain, weighted by $S_{i}$. That is,

$$
\begin{gathered}
h_{\text {plate }}=\frac{1}{S_{\text {tot }}} \sum_{i=1}^{n} S_{i}\left(\frac{S_{i}}{\left(N_{i}+1\right)}\right), \\
S_{\text {tot }}=\sum_{i=1}^{n} S_{i} .
\end{gathered}
$$

These measurements were performed in more than 300 grains of different sizes. The relation between $d$ and $h_{\text {plate }}$ is plotted in Figure 2 on a log-log scale. Each point represents the average sizes measured for a grain of a given sample.

Figure 2 shows that $h_{\text {plate }}$ is independent of $d$ for $d>100 \mu \mathrm{m}$. However, a strong decrease of $h_{\text {plate }}$ is observed as $d$ falls below $100 \mu \mathrm{m}$. This behavior is due to the difficulty of developing the transformation in reduced domains. So, the mean plate size decreases to generate more geometric possibilities to accommodate the transformation strain and match to the structure at the grain boundaries.

It is interesting to note that the break-point of this behavior, which is plotted in Figure 2, occurs at $d=100 \mu \mathrm{m}$. This is consistent with the fact that the $M_{s}$ decreases, when $d$ is less than $100 \mu \mathrm{m} .{ }^{3,4,18}$ This agreement supports the idea that the size effect on the martensitic transformation appears below this value of grain size. 


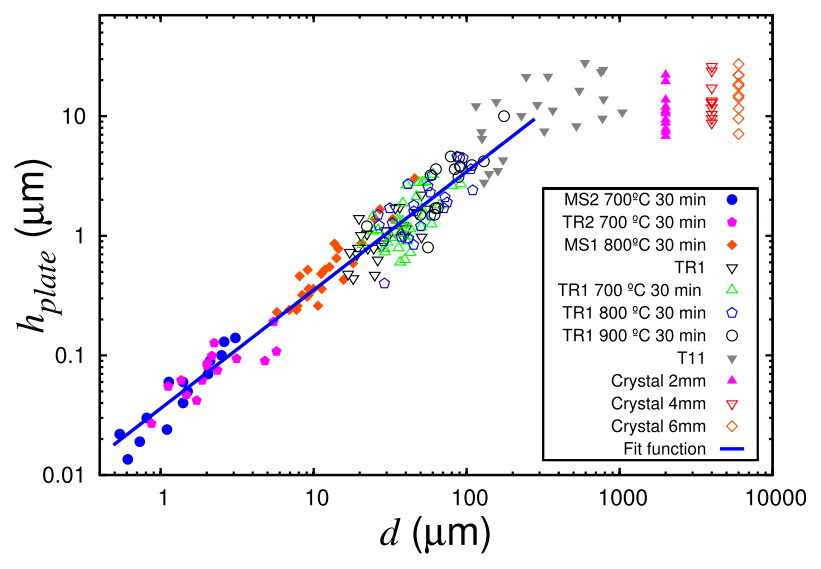

FIG. 2. Experimental measurements of the $h_{\text {plate }}$ as a function of the $d$.

In order to find a functional relation between these parameters, the experimental data was fitted, over the range of $d$ below $100 \mu \mathrm{m}$, by the power law $h_{\text {plate }}(d)=A d^{B}$, where $A$ and $B$ are the fitting parameters. The function was fitted using least-square method on the logarithmic values of the measured points, giving $A=(0.036 \pm 0.002)$ and $B=(0.99 \pm 0.02)$. It is interesting to note that $B$ is very close to 1 , so it can be assumed that there is a linear relation between $h_{\text {plate }}$ and $d$. Therefore, it can be concluded that the relation between these two characteristic sizes is

$$
h_{\text {plate }}(d)=0.036 d \text {. }
$$

It is interesting to note that the linear relation given by Eq. (3) corresponds to the model used by Turteltaub and Suiker $^{14}$ for a TRIP steel, where the aspect ratio $c$ (relation between thickness of a martensitic plate and the grain diameter) was estimated to be 0.05 . This value is close to the value of 0.036 found in the current experimental study. On the other hand, a linear relationship disagrees with the potential functions reported by Khan ${ }^{7}$ and Waitz et al. ${ }^{15}$ Nevertheless, in the former work, the potential relationship was determined fitting experimental data over a limited range of $d$ between 250 and $5000 \mu \mathrm{m}$. Whereas, the latter work obtained a relation $h_{\text {plate }}$ $\approx d^{1 / 2}$ based on a theoretical energy minimization criterion, which agrees with an experimental measure of these magnitudes on a nanograin length scale $\left(d=50 \mathrm{~nm}\right.$ and $h_{\text {plate }}$ $=2.0 \pm 0.5 \mathrm{~nm}$ ). It is interesting to note that this experimental measure of the nano-grains morphology is consistent with Eq. (3). Also, a linear relation between $h_{\text {plate }}$ and $d$ was previously suggested by Perkins, ${ }^{21}$ who observed the same grain plate size relationship in two images with very different grain sizes.

The experimental results ${ }^{2-4}$ show that if the grain size is reduced below $100 \mu \mathrm{m}$, an additional overcooling is necessary to produce the phase transformation $\left(M_{s}\right.$ decrease). This means that the sample is overcooled to increase the driving force to overcome the energy barrier generated by different mechanisms, such as elastic accommodation, interface energy, and dissipative processes (e.g., interaction with defects, interfaces friction, etc.).

The experimental relation between $d$ and $h_{\text {plate }}$ presented in Eq. (3) allows us to evaluate the change of the m-m interface area per unit volume as $d$ is reduced. Thus, the interface energy density per unit volume behavior can be analyzed.
For this purpose, it is necessary to develop a theoretical model of the grains, which takes into account the change of total surface area of the m-m interface. It can be assumed that the grains are spherical with a simple arrangement of parallel martensitic plates, as shown in Figure 3 (inset). The $\mathrm{m}-\mathrm{m}$ interfaces are equidistant and separated by $h_{\text {plate, }}$, which is defined by Eq. (3). This model represents the microstructural parameter averages, and although this may seem very rough, it usefully captures size effects.

The total surface area of the m-m interfaces inside the grain $\left(A_{\text {tot }}^{m-m}\right)$ is calculated using the expression ${ }^{15}$

$$
A_{t o t}^{m-m}(d, N)=\frac{\pi}{2} d^{2}\left(\frac{N^{2}-1}{3 N}\right),
$$

where $N$ is the number of m-m interfaces. From Eq. (3), it is clear that $N=d / h_{\text {plate }}=28$. It follows that $A_{\text {tot }}^{m-m}$ depends only on $d$. The assessment of the interface energy density per unit volume is made using the following expression:

$$
E^{m-m}=\gamma^{m-m} \frac{A_{t o t}^{m-m}(d)}{V(d)}=\left(\frac{N^{2}-1}{N}\right) \frac{\gamma^{m-m}}{d},
$$

where $V(d)$ is the volume of the spherical grain and $\gamma^{m-m}$ is the $\mathrm{m}-\mathrm{m}$ interface energy per unit area. Values of $\gamma^{m-m}$ between $0.02 \mathrm{~J} / \mathrm{m}^{2}$ and $0.5 \mathrm{~J} / \mathrm{m}^{2}$ were calculated for $\mathrm{Cu}-\mathrm{Al}-\mathrm{Ni}$ in the $18 \mathrm{R}$ martensitic structure, depending on the crystallographic compatibility between the different martensitic variants. $^{22}$ Moreover, when Shilo et $a l .{ }^{23}$ determined the thickness and energy of type-I twin boundaries in $\mathrm{Cu}-\mathrm{Al}-\mathrm{Ni}$ single crystals by fitting simulated displacement fields to AFM surface topography measurements, they obtained a value of $\gamma^{m-m}=0.07 \mathrm{~J} / \mathrm{m}^{2}$.

Figure 3 shows $E^{m-m}$ as a function of $d$ for the different values of $\gamma^{m-m}$. It is observed that $E^{m-m}$ is significant for the $d$ lower than $10 \mu \mathrm{m}$. It is interesting to note that over this range, a reasonable correspondence was verified between the rough grain model (grains with a simple arrangement of parallel martensitic plates) and the experimental observations (Figure 1(b)). It must be stressed that the linear relation between the $h_{\text {plate }}$ and $d$ yields a scaling behavior between the $\mathrm{m}-\mathrm{m}$ interface energy and grain size of $E^{m-m} \approx 1 / d$.

To understand size effects, it is interesting to assess the transformation hardening produced by the $\mathrm{m}-\mathrm{m}$ interface-

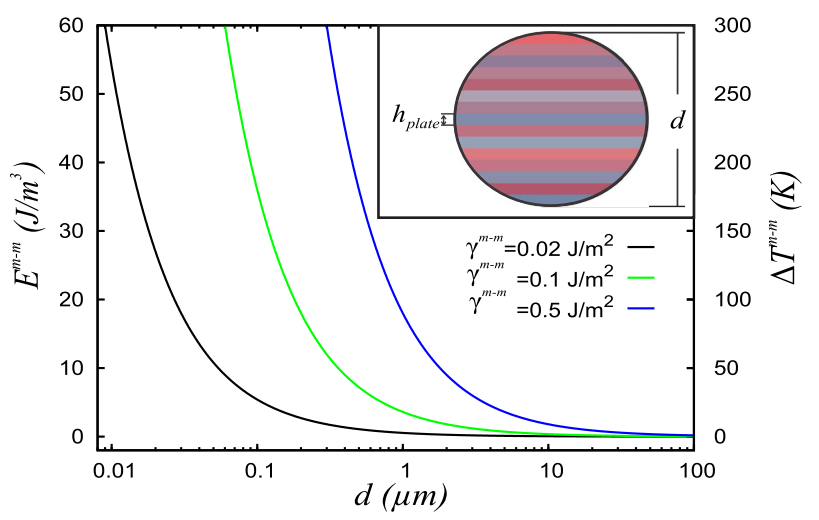

FIG. 3. Grain model (inset), interface energy density per unit volume $\left(E^{m-m}\right)$ and overcooling $\left(\Delta T^{m-m}\right)$ to overcome the energy barrier imposed by the m-m interfaces as a function of $d$. 
energy increase, which is yielded through the martensitic plate refinement. The driving force $D F^{m-m}$ to overcome the energy barrier imposed by this mechanism is given by

$$
D F^{m-m}=\Delta S\left(\Delta T^{m-m}(d)\right)=E^{m-m},
$$

where $\Delta S=-2 \times 10^{5} \mathrm{~J} / \mathrm{m}^{3} \mathrm{~K}$ is the entropy change between the two phases ${ }^{24}$ and $\Delta T^{m-m}$ is the overcooling to produce the $D F^{m-m}$ increase. The value of $\Delta T^{m-m}$ needed to overcome the energy barrier imposed by the $\mathrm{m}-\mathrm{m}$ interfaces is plotted in the right axis of Figure 3.

As already noted, the energy $E^{m-m}$ is appreciable only when $d$ is less than $10 \mu \mathrm{m}$. Although, it is possible to analyze the austenitic stabilization in nanograins. For instance, in a $\mathrm{Cu}$-Al-Ni grain of $d=10 \mathrm{~nm}$, the overcooling to overcome the energy barrier generated by the $\mathrm{m}-\mathrm{m}$ interface energy was $280 \mathrm{~K}$ (using the smaller value of $\gamma^{m-m}=0.02 \mathrm{~J} / \mathrm{M}^{2}$ ). Therefore, this high energy barrier will stabilize the austenitic phase of $\mathrm{Cu}$-Al-Ni nano-size grains.

Summarizing, a linear relationship between the average plate width and grain size was obtained $\left(h_{\text {plate }}(d)=0.036 d\right)$, through a systematic experimental method based on evaluation of the plate size in domains. This experimental relationship is a useful input parameter for theoretical models that study size effects in martensitic transformations. Using a rough grain model, the energy barrier (produced by the martensiticmartensitic interface energy) as a function of the grain size was assessed. Also, the overcooling required to overcome the energy barrier was calculated. The energy barrier is appreciable in grains smaller than $10 \mu \mathrm{m}$ and it is large enough to stabilize the austenitic phase in materials with nanograins.

The authors would like to thank Daniel Castelani and Fernando Ugo for these valuable collaborations in the development of the instrumentation. They express grateful acknowledgment to Conicet (Argentina), financial support from the "Agencia Nacional de Promoción Científica y Tecnológica," Argentina (under Grant Nos. PICT 2140 and PICT 1341) and ECOS program (Project No. A10E02).

${ }^{1}$ G. N. Sure and L. C. Brown, Metall. Trans. A 15, 1613 (1984).

${ }^{2}$ K. Seki, H. Kura, T. Sato, and T. Taniyama, J. Appl. Phys. 103, 063910 (2008).

${ }^{3}$ W. Jianxin, J. Bohong, and T. Y. Hsu, Acta Metall. 36, 1521 (1988).

${ }^{4}$ K. Mukunthan and L. C. Brown, Metall, Trans. A 19, 2921 (1988).

${ }^{5}$ A. Shibata, H. Jafarian, and N. Tsuji, Mater. Trans. 53, 81 (2012).

${ }^{6}$ A. Khan, M. Brabers, and L. Delaey, Mater. Sci. Eng., A 15, 263 (1974).

${ }^{7}$ A. Khan, J. Mater. Sci. 9, 1290 (1974).

${ }^{8}$ T. Waitz and H. P. Karnthaler, Acta Mater. 52, 5461 (2004).

${ }^{9}$ Y. Chen and C. A. Schuh, Acta Mater. 59, 537 (2011).

${ }^{10}$ N. Ozdemir, I. Karaman, N. Mara, Y. Chumlyakov, and H. Karaca, Acta Mater. 60, 5670 (2012).

${ }^{11}$ S. M. Ueland and C. A. Schuh, Acta Mater. 61, 5618 (2013).

${ }^{12}$ M. Tomozawa, H. Kim, A. Yamamoto, S. Hiromoto, and S. Miyazaki, Acta Mater. 58, 6064 (2010).

${ }^{13}$ J. Barth, B. Krevet, and M. Kohl, Smart Mater. Struct. 19, 094004 (2010).

${ }^{14}$ S. Turteltaub and A. Suiker, Int. J. Solids Struct. 43, 7322 (2006), sizedependent Mechanics of Materials.

${ }^{15}$ T. Waitz, T. Antretter, F. D. Fischer, and N. K. Simha, J. Mech. Phys. Solids 55, 419 (2007).

${ }^{16}$ A. Diestel, A. Backen, U. K. Rler, L. Schultz, and S. Fhler, Appl. Phys. Lett. 99, 092512 (2011).

${ }^{17}$ H. Petryk and S. Stupkiewicz, J. Mech. Phys. Solids 58, 390 (2010).

${ }^{18}$ J. Dutkiewicz, T. Czeppe, and J. Morgiel, Mater. Sci. Eng., A 275, 703 (1999).

${ }^{19}$ J. Malarría, C. Elgoyhen, P. Vermaut, P. Ochin, and R. Portier, Mater. Sci. Eng., A 440, 763 (2006).

${ }^{20}$ C. E. Sobrero, R. Bolmaro, J. Malarría, P. Ochin, and R. Portier, Mater. Sci. Eng., A 481-482, 688 (2008).

${ }^{21}$ J. Perkins, Metall. Trans. A 13, 1367 (1982).

${ }^{22}$ J. Zhang, Y. Zheng, B. Huang, W. Cai, and L. Zhao, Mater. Sci. Eng., A 251, 150 (1998).

${ }^{23}$ D. Shilo, A. Mendelovich, and V. Novák, Appl. Phys. Lett. 90, 193113 (2007).

${ }^{24}$ R. Romero and J. L. Pelegrina, Materials Science and Engineering: A 354, 243 (2003). 